\title{
Law Games: Defeasible Rules and Revisable Rationality
}

\author{
Bruce Chapman
}

\author{
Version Publisher's Version
}

Citation Bruce Chapman, "Law Games: Defeasible Rules and Revisable (published version) Rationality" (1998) 17 Law and Philosophy 443.

Publisher's Statement This article has been reproduced with the permission of Springer International. The final publication is available on https://doi.org/10.2307/3505089

\section{How to cite TSpace items}

\footnotetext{
Always cite the published version, so the author(s) will receive recognition through services that track citation counts, e.g. Scopus. If you need to cite the page number of the author manuscript from TSpace because you cannot access the published version, then cite the TSpace version in addition to the published version using the permanent URI (handle) found on the record page.
}

This article was made openly accessible by $U$ of $T$ Faculty. Please tell us how this access benefits you. Your story matters. 
BRUCE CHAPMAN

\section{LAW GAMES: DEFEASIBLE RULES AND REVISABLE RATIONALITY*}

\section{INTRODUCTION}

Imagine that you and I are both rational players in a game. Suppose, further, that we have common knowledge of our rationality (hereafter CKR). This means that each of us knows that the other is rational (first order knowledge), that each knows that the other knows this (second order knowledge), that each knows that the other knows that the other knows this (third order knowledge), and so ad infinitum. ${ }^{1}$ Suppose now that one of us makes what appears to be an irrational move in the game. What are we to make of this? Can our overarching framework of rationality accommodate such a possibility? Or does the irrational move just mean that, whatever we might have believed, there never really was CKR in our game after all?

Certainly the notion of belief, and the idea that we might have only a common belief in our rationality (or CBR), appears to open up some space for irrational moves in a way that CKR does not. Neither you nor I need actually be rational in a game characterized by CBR. Both of us might be irrational even though I believe you to be rational, that you believe this of me, that, further, each of us believes this of each other's first order beliefs, and so on. Of course,

$\star$ I am grateful to John Broome, Lewis Kornhauser, and Jerry Postema for helpful comments.

1 The use of the term "common knowledge" seems to have originated in David Lewis, Convention (Cambridge: Harvard University Press, 1969). For good discussion of its importance for game theory generally, see Cristina Bicchieri, Rationality and Coordination (Cambridge: Cambridge University Press, 1993), pp. 39-43.

Law and Philosophy 17: 443-480, 1998.

(C) 1998 Kluwer Academic Publishers. Printed in the Netherlands. 
if one of us were to make the irrational move in such a game, we might want to change our beliefs. But, unlike for CKR, at least there is some logical space for thinking about the irrational move. We can make sense of it with our CBR framework: we were simply mistaken in the first order beliefs that we had. Indeed, it is the realization that we were mistaken in this way which prompts us to change our beliefs that we were both rational in what we do.

The problem, however, is knowing how to go on after we have made some logical space for the irrational move in this way. For once, given an irrational move, we have taken on the idea that one or both of us is not actually rational, then it seems that our overarching framework of rationality has lost its analytical purchase on the problem. We can accommodate or "make sense of" an irrational move in a way that the CKR framework cannot, but only in the limited and exclusive sense that says "That move was not rational" or "You were not rational to make that move". We cannot comprehend the fact of irrationality within a framework that only assumes rationality. ${ }^{2}$ On the other hand, if we go back to assuming that we are both rational, so that the framework can provide some systematic account of behaviour, then, even if we limit ourselves to CBR, there would be the same problem as with CKR. Any apparently irrational move would either run counter to our common beliefs or be at odds with our assumption that we are both rational in what we do.

There is, of course, another possibility. We might both be rational in fact, but not have CBR. This opens up the possibility for one of us to make what appears to be an irrational move (and which would be irrational under CBR), although it is not irrational so long as we do not have CBR. It may be rational for me to make this move, for example, if I believe that you are irrational. ${ }^{3}$ After all,

\footnotetext{
2 If a player finds herself at a point which is inconsistent with the theory of the game she is using, then she is deprived of a theory upon which to base her decisions. This has the effect of leaving the other players in the game without a theory as well, since they will not be able to predict what she will do and, therefore, are unable to decide what to do themselves. On this, see Philip J. Reny, "Common Knowledge and Games with Perfect Rationality," Proceedings of the Philosophy of Science Association 1988, 2 (East Lansing: Philosophy of Science Assn., 1989), p. 363.

3 This is to introduce a mistake at the level of first order beliefs. Fully analogous arguments could be provided for a case of mistake at any other order of
} 
your apparent irrationality opens up a whole new set of possible strategic interactions to me that were not (seemingly) available when I believed you to be rational. And it may be rational now for me, in light of these different beliefs, to move, or choose, differently. Moreover, it might even be rational for you (knowingly) to play your apparently irrational part within my scheme of mistaken beliefs, thereby confirming (it seems to me) my belief that you are not in fact rational. After all, my rational response to my (now) mistaken belief in your irrationality opens up a whole new range of possible strategic interactions for you as well. And, in light of these different beliefs, it might actually be rational for you now to act in what (to me) is an apparently irrational way. This might be so even though the change in beliefs is mine, not yours. But that should not be surprising; strategic interaction will often require us to choose in light of what we believe others to believe.

This last possibility for accommodating irrational behaviour is the one typically used by game theorists. CKR seems to leave no room for irrational behaviour and, in certain sorts of games like the finite repeated prisoner's dilemma (to be discussed more below), leads to some very implausible results when only rational behaviour is permitted theoretically. On the other hand, relaxing CKR by relaxing one's assumptions about any one player's rationality has the danger of leaving game theory with very little to say about either that player's behaviour or, further, the behaviour of any other player who is seeking to predict the irrational player's behaviour and interact rationally with him. Thus, it seems the only available game theoretic strategy is to maintain actual rationality in each and every player, but relax the commonality of belief in, or knowledge of, this rationality across the players.

In this paper I want to suggest a quite different strategy for the theoretical accommodation of seemingly irrational moves. Oddly, perhaps, it is one which is suggested by the theory of legal reasoning and adjudication, theory that would seem not to be all that connected to the theory of games. But legal theory has long been grappling with a very similar sort of problem, namely, how to accommodate

belief. For example, I might believe that you believe me to be irrational, something which might allow me rationally to make what appears (to you) to be an irrational move. 
the "exception" in relation to "the rule". Theorists of adjudication and legal reasoning, just as much as game theorists, also seem to want to have it both ways. They want to make sense of the exception as an irregularity (or irrationality) without at the same time losing sight of the very thing, the rule, which allows them to make sense of any regularity (or rationality) at all. The question for this paper is whether there is anything which game theory can learn from legal theory about how most sensibly to accommodate a seemingly irrational possibility within an otherwise rational framework.

The paper is organized as follows. In Section II, after a very brief review of two theories of legal rules and exceptions, I propose a general model of defeasible legal rules. Defeasibility, I argue, has a very special structure which allows both for the sequenced priority of a rule and the possibility of its being overridden by an exceptional (but subsequent or secondary) consideration. It is this dual aspect of defeasible rules which, at one and the same time, can provide for both the categorical priority of rules and their non-absolutism, that is, their ability to accommodate exceptions. My claim is that this dual nature is essential to any proper understanding of legal rules and legal reasoning.

In Section III I return to the theory of games. Beginning with an example of backward induction, where the problem is most transparent, I show that there is a tension in game theoretic reasoning between the rationality that is assumed still to exist at the end of a finite repeated game (from which the backward induction argument begins) and the irrationality that must be in place from the beginning of the game if the end of the repeated game is actually to be reached. Then I argue that this same tension exists more generally under CKR and CBR when CKR and CBR are advanced as rationalizations of the Nash equilibrium strategies as "the way to play" in a one-shot game. These difficulties, I argue, call for a relaxation of CKR and CBR.

In Section IV I argue for a special way to relax CKR and CBR which is analogous to law's use of defeasible legal rules. That is, I argue that, confronted with an irregularity or irrationality, instead of relaxing the commonality of beliefs in the regularity or rationality conditions in the way that is conventionally assumed by game theory, we should instead preserve the commonality of belief but 
relax the very conception of regularity or rationality itself. Such a response is not only more systematic and less ad hoc than an arbitrary introduction of asymmetric (non-common) beliefs, it also encourages us to re-think what rationality might require even in those games where CKR has no real role to play in rationalizing a solution to the game. For example, in the one-shot prisoner's dilemma, where each player has a dominant strategy to choose noncooperation, that is, to choose non-cooperation regardless of her beliefs about the rationality of the other player, it may be that a revisable or defeasible conception of rationality can, in principle, allow for some (conditionally) cooperative play, the very sort of thing that we seem to observe in such games when they are played in fact. ${ }^{4}$ The paper finishes with some brief concluding remarks in section $\mathrm{V}$.

\section{RULES, EXCEPTIONS, AND THE STRUCTURE OF DEFEASIBILITY}

One of the better known characterizations of legal rules is that provided by Ronald Dworkin in his book Taking Rights Seriously. ${ }^{5}$ Legal rules, according to Dworkin, have a different logical structure from legal principles. While both are standards used to justify particular legal results in particular circumstances, they differ in the character of direction that they give. While legal principles have a dimension of "weight", and merely incline a decision in one direction rather than another, rules are more categorical, necessitating a particular decision if they apply at all:

Rules are applicable in all-or-nothing fashion. If the facts a rule stipulates are given, then either the rule is valid, in which case the answer it supplies must be accepted, or it is not, in which case it contributes nothing to the decision. ${ }^{6}$

\footnotetext{
${ }^{4}$ For an indication that non-economists (at least) tend to cooperate more than would be predicted by rational choice theory in a one-shot prisoner's dilemma game, see Robert Frank, Thomas D. Gilovich, and Dennis T. Regan, "Does Studying Economics Inhibit Cooperation?," Journal of Economic Perspectives 7 (1993), p. 159.

5 Ronald Dworkin, Taking Rights Seriously (London: Duckworth and Co., 1977), Chapters 2 and 3.

${ }^{6} I d$., at 24.
} 
Does this account of rules leave any room for exceptions? Dworkin goes on:

Of course, a rule may have exceptions ... However, an accurate statement of the rule would take [these exceptions] into account, and any that did not would be incomplete. If the list of exceptions is very large, it would be too clumsy to repeat them each time the rule is cited; there is, however, no reason in theory why they should not all be added on, and the more there are, the more accurate is the statement of the rule. ${ }^{7}$

Thus, there can be exceptions to a rule, but only in this very limited sense. Strictly speaking, the exceptions do not so much apply to the rule as constitute an essential part of it. In Claire Finkelstein's words, "the rule swallows the exception". 8

Dworkin's characterization of the different logical nature of rules and principles has not been without its detractors, ${ }^{9}$ but it is interesting to note that in Frederick Schauer's much more recent account of the nature of rules the "all-or-nothing" characterization of rules persists. ${ }^{10}$ Schauer argues that the only meaningful conception of rules qua rules is one which sees them as "entrenched". 11 According to Schauer, a conception of rules which allows for their abandonment in the face of a particular "recalcitrant experience", 12 for example, a case in which the justification lying behind the rule would be better served by jettisoning the rule than by observing it, is no account of rules at all. For rules to operate as rules, the argument goes, they must have at least some power, or "weight", 13 to resist a call by the background justification that the recalcitrant experience be treated other than according to what the rule requires. Otherwise,

\footnotetext{
7 Id., at 24-25.

8 Claire Finkelstein, "When the Rule Swallows the Exception" (manuscript, School of Law, Berkeley, 1998), passim. I am particularly grateful to Claire Finkelstein for her analysis of the accounts of both Dworkin and Schauer of the relationship between rules and exceptions.

9 See, e.g., Joseph Raz, "Legal Principles and the Limits of Law," Yale Law Journal 81 (1972), p. 823.

10 Frederick Schauer, Playing By the Rules (Oxford: Clarendon Press, 1991).

11 Id., at 52.

$12 I d$., at 39.

$13 I d$, at $117-118$.
} 
the rule's background justification is everything and the rule adds nothing. ${ }^{14}$

Schauer's understanding of how it is that exceptions relate to a rule is also very close to Dworkin's. Again, the idea is that the rule, properly and completely articulated as a rule, must contain all the various "unless" clauses that are relevant to the application of the rule. ${ }^{15}$ A rule with such a list of "unless" clauses, while quite possibly cumbersome and complicated, is no less a rule. However, if some "unless" qualification, not articulated as part of the rule prior to its application, is used to ground an exception to the rule at the moment of its application, then Schauer argues that there is essentially no rule. ${ }^{16}$ Again, the idea is that the rule qua rule must have some autonomy from the background justifications which inform the rule and its various exceptions. Without that, there are only the background justifications and nothing more.

Now, of course, there is the difference that Schauer has much more sympathy for the "model of rules" than does Dworkin. ${ }^{17}$ Where Dworkin would abandon rules in light of the overall constellation of legal principles that best fits those rules and gives them their most compelling justification, Schauer will argue that there are reasons to follow entrenched rules independent of those justifications.

But the point of this brief survey of their views is not to dwell on the differences between Dworkin and Schauer, but rather to highlight a view they have in common, which is that exceptions do not really exist apart from rules at all. At most, the "unless" clauses that

\footnotetext{
14 Some (including Schauer himself; see id., at 115) will see this as a key difference between Schauer and Dworkin. For Dworkin, principles have weight, but rules do not. For Schauer, rules can also have weight; they simply do not give into background principles or justifications at every opportunity. That they do not is Dworkin's reason for rejecting the model of rules in favor of the direct application of those principles which justify the rules. By contrast, that they do not is Schauer's reason for accepting the model of rules; there are good reasons, he says, for entrenchment. But what Dworkin and Schauer have in common is the idea that rules, at least to some extent, resist the direct application of background principles and justifications.

15 Id., at 115.

16 Id., at 116.

17 See id., Chapter 7, for Schauer's arguments in favor of having entrenched rules.
} 
articulate the exceptions to a rule are components of the rule. It may be, of course, that to specify fully all the circumstances for the rule's application will be cumbersome. Thus, as a practical matter, a rule may not always be completely articulated and, for most cases, this incompleteness will not matter. But, in principle at least, all the relevant exceptions could be articulated and the apparently "recalcitrant experience" simply subsumed under the rule.

However, this account of the structure of "unless" clauses, and how they relate to the rules and legal categories they are said to qualify, is very different from the one provided by H. L. A. Hart. ${ }^{18}$ Hart argued that that there is a special sort of relationship that exists between legal rules and their exceptions and it is one characterized by the peculiarly legal notion of defeasibility. But defeasibility, as we shall now see, provides for a structure which is very different from the one that merely collapses an exception into a more complete articulation of the rule. Indeed, given the collapse of the one into the other that both Dworkin and Schauer seem to contemplate, it seems odd to think that there could be any real relationship between rules and exceptions at all. Relationship seems to presuppose some sort of independence in the things related.

Although he believed that the notion of defeasibility had wide application in the law, Hart developed the idea most explicitly with reference to the concept of a "contract". For Hart, as much for other legal scholars, there is the usual list of positive conditions required for the existence of a valid contract (e.g., at least two parties, an offer by one, its acceptance by the other, consideration on both sides). However, knowledge of these conditions does not, according to Hart, give a full understanding of the concept of contract. What is also needed is some knowledge of the various ways in which the claim that there is a contract might be defeated. Such defences to the claim would include, for example, that there was fraudulent misrepresentation, duress, or lunacy. Hart suggested that the concept of contract was best explained by setting out a list of conditions which are normally necessary and sufficient for the existence of a valid

18 H. L. A. Hart, "The Ascription of Responsibility and Rights", in Anthony Flew (ed.) Essays in Logic and Language (First Series) (Oxford: Basil Blackwell, 1960), pp. 145-166. 
contract, together with a series of "unless" clauses that spell out the conditions under which this existence claim is defeated.

Now Hart recognized that those theorists who show an "obstinate loyalty to the persuasive but misleading logical ideal that all concepts must be capable of definition" 19 will be constantly tempted to reduce an "irreducibly defeasible" 20 concept to a set of conditions which are always necessary and sufficient for the concept's deployment in particular circumstances. It is this notion of concept deployment, and more particularly this reductive version of concept deployment, which brings us back to the idea that collapses an exception into the rule. What Hart had in mind here was the very same theoretical ploy as that used by Dworkin and Schauer which would accommodate defeasibility in one step by positing the absence of the defeating conditions as some of the necessary conditions for the concept's proper use. Where Dworkin and Schauer talk of rules providing a full specification of their exceptions, Hart had in mind those who would reduce a concept to that definitive set of conditions which are always (i.e., without exception) necessary and sufficient for the application of the concept.

However, Hart recognized that such reductive interpretations of legal concepts and rules only serve to obscure and ultimately misrepresent their essentially defeasible nature. As its borrowing from the world of property law suggests, a legal concept or rule is defeasible if (i) it is subject to termination or defeat in the face of certain contingencies, and (ii) it survives intact if no such contingencies mature. The representation of (the absence of) the defeating conditions as necessary conditions for the positive application of the concept or rule fails to make sense of the idea in (ii) that, until (or unless) some factual evidence on the defeating conditions is forthcoming (one way or the other), the concept or rule simply does apply to the facts already at hand. In other words, the reductive interpretation of a concept or rule, while accommodating the defeating conditions in (i), fails to account for the equally essential sequenced nature of defeasibility which is present in virtue of (ii).

Moreover, it is the priority of a defeasible rule over its defeating conditions in sequence which makes sense of the "all-or-nothing"

\footnotetext{
19 Id., at 152.
}

20 Id., at 150. 
character of a rule that both Dworkin and Schauer emphasize in their analyses. Suppose, for example, that we had to choose between two alternative social states $x$ and $y$ first, that is, before going on to compare the winner in that choice with some other alternative social state $z$. Thus, the choice sequence is, first, to consider the partition of the alternatives $(x, y)$, and then to consider either the partition $(x, z)$ or the partition $(y, z)$, depending on which alternative survives the first choice. In such circumstances one can easily imagine that some normative criterion or rule might be put "at issue" in the choice between $x$ and $y$ which would simply be irrelevant to, or not at issue in, the subsequent choices between, say, $x$ and $z$ or $y$ and $z$. Some normative criteria are like this: they are simply applicable to some partitions (or sets of alternatives available for choice) and not others. In this respect, therefore, they are "all-or-nothing", or categorical, in their application; an economist might be tempted to say that they are "partition dependent". 21

For example, suppose that the three choices $x, y$, and $z$ which we have been considering are applicants for some money award, say $\$ 1000 .{ }^{22}$ We might consider that in the choice $(x, y)$ we should give the award to $x$ since candidate $x$ will do more good with the $\$ 1000$ award than candidate $y$. And, for fully analogous reasons relating to the greater good, we might consider that in the choice $(y, z)$ we should give the award to candidate $y$. Thus, we would choose $x$ over $y$ and $y$ over $z$. So far we have used no partition dependent normative criterion. But now suppose that candidate $x$ owes candidate $z \$ 1000$, that is, a sum exactly equal to the award that is about to be given away. In such circumstances we might think that it would be silly or wasteful, first, to award the $\$ 1000$ to $x$ rather than $z$ because $x$ will

21 Albeit not sympathetically. The term is usually "path dependent", which refers to partition dependent choices coming in sequence. But the general point is the same: according to the economist, path or partition dependent choices are less than ideal. See infra note 23.

22 The following example is borrowed from James F. Reynolds and David C. Paris, "The Concept of 'Choice' and Arrow's Theorem," Ethics 89 (1979), p. 363. For comparable examples of partition dependent choice, see I. Levi Hard Choices (Cambridge: Cambridge University Press, 1986), p. 105. Also for a more detailed characterization of defeasibility in partition dependent terms, see Bruce Chapman, "Law, Incommensurability, and Conceptually Sequenced Argument" University of Pennsylvania Law Review 146 (1998), p. 1487. 
do more good with the award, and then require that $x$ pay that same sum over to $z$, say, as a matter of corrective justice. Rather, we might say that in a choice between $x$ and $z$ corrective justice should prevail and that we should simply award the money to $z$ rather than $x$ in the first instance. Now, this matter of corrective justice is clearly only an issue between $x$ and $z$, and only relevant, therefore, to partitions where $x$ and $z$ are candidates for choice. So now we might choose $x$ over $y$ (because of the greater good), $y$ over $z$ (same reason), and $z$ over $x$ (because of corrective justice), in an apparent violation of transitivity. But we can hardly say that what has happened here is in any way irrational. Rather, each choice from each partition makes perfect sense according to what that particular partition puts at issue.

Indeed, it may appear that we can even avoid certain issues altogether by arranging the partitions of the alternatives in certain sequences or paths. If we begin with the partition $(x, z)$, for example, corrective justice becomes an issue and candidate $x$ may be eliminated from further consideration. In the next choice $(y, z)$, we would go on to choose $y$ as the candidate who would do more good with the award. On the other hand, if we begin with the partition $(y, z)$, then we might choose $y$ because he will do more good with the award than $z$. Then in the final choice $(x, y)$, we would choose $x$ because he will do even more such good with the award. In this last sequence the corrective justice issue between $x$ and $z$ seems to be avoided altogether, something which, contrary to the first sequence, allows $x$ to be the final choice. Thus, in this way it seems that choice can, sensibly (rationally?), be not only partition dependent but path (or sequence) dependent as well. ${ }^{23}$

\footnotetext{
23 Kenneth Arrow invoked his collective rationality condition, transitivity of the social preference relation, in part to avoid path dependent social choices. Such path dependence, he seemed to think, would make the final choice of some alternative an (historically) arbitrary matter; see K. J. Arrow, Social Choice and Individual Values (New Haven: Yale University Press 1963), p. 120. But not all path dependent choice need be arbitrary path dependent choice; indeed, some "paths" may make much more sense than others, especially if they are "conceptually sequenced". On the idea of a conceptually sequenced path dependent choice, see infra, text following note 25; Chapman, supra note 22; Bruce Chapman, "Pluralism in Tort and Accident Law: Towards a Reasonable Accommodation" in Gerald J. Postema (ed.) Philosophy and the Law of Torts (Cambridge: Cambridge University Press, 1999); and Bruce Chapman, "More Easily Done Than Said: Rules, Reasons, and Rational Social Choice", Oxford Journal of Legal Studies
} 
However, it is probably a mistake to think that we are free to select just any choice sequence or path that we want. Indeed, the award example can be used to suggest that some choice paths provide us with more sensible (i.e., more coherent or coordinated) accommodations of the plurality of (partition-dependent) choice criteria that seem to be at stake in the choice problem than others. We might feel, for example, that in the award problem the choice is truly among all three candidates, that is, that the choice is, ultimately, over the triple $(x, y, z)$. If that is so, then there is something artificial about using a partitioning or sequencing of the three alternatives that completely "avoids" corrective justice as an issue, that is, that avoids any joint consideration of the two alternatives $x$ and $z$ together. Thus, the second of the two choice sequences mentioned in the previous paragraph can be eliminated from consideration.

But what about the two sequences that preserve corrective justice as an issue, namely, "First $(x, z)$, then $(y, z)$ " and "First $(x, y)$, then $(x, z)$ "? While both of these sequences preserve corrective justice (or the separate partitioning of $x$ and $z$ ) as an issue, the former puts that issue first and the latter puts it second in the choice sequence. Is there any reason to select one choice sequence rather than the other, that is, a particular path as well as a particular partition? There may be. For notice that if the latter choice path or sequence is chosen, then, first, $x$ will be chosen over $y$ because of the greater good that $x$ can do with the award. But then, in the second step of the sequence, $x$ will be eliminated from consideration in the presence of $z$ because of corrective justice. The final result in choosing $z$ is that corrective justice dominates completely as a choice criterion, this despite the fact that there is another possible choice, namely $y$, which is also consistent with the requirements of corrective justice, and which could achieve greater good. Thus, this choice sequence provides a less than perfectly coherent or coordinated accommodation of the two choice criteria that seem genuinely and independently to be at stake here. On the other hand, the former choice sequence, which puts corrective justice first in the sequence, requires $x$ to be eliminated in the presence of $z$, but then allows $y$ to be chosen over $z$ in

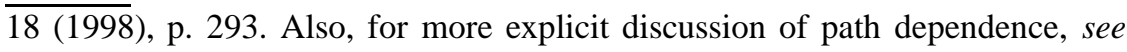
Charles Plott, "Path Independence, Rationality, and Social Choice" Econometrica 41 (1973), p. 1075. 
the next step of the sequence since $y$ will do more good with the $\$ 1000$ award. It is arguable, surely, that this path through the relevant choice partitions provides for a more sensible and coordinated response to the two different choice criteria that are at stake in the problem. We shall have reason to revisit this idea of sensible choice paths at the end of this section, when we consider the conceptual presuppositions that animate the notion of legal excuses.

However, before doing so, it is worth emphasizing that while some normative criteria might be interpreted as partition or path dependent or, in this now more precisely defined sense, categorical in their application, they need not have any absolute priority over other criteria that might also be applicable to the choice. Again, to use the above three candidate example, it might be that our concerns for corrective justice, or what is right between any two parties as a transactional matter, will make it problematic (or, at least, wasteful) to choose candidate $x$ for the award in the presence of candidate $z$. But one can imagine that the greater amount of good that $x$ will do with the award than $z$ could get so large as to make it inappropriate to let the concerns of corrective justice carry the day, even in the partition $(x, z)$ where corrective justice so categorically applies. In this sense, therefore, the categorical applicability (a partition dependent idea), or categorical priority (a path dependent idea), of some criterion can be non-absolute, that is, subject to defeasance by some other criteria. But this, of course, is simply to add the second of Hart's two features of defeasibility, namely the possibility of defeasance, to the sequenced or categorical priority that is present in the first of defeasibility's two features. ${ }^{24}$

Thus, it is in this sense that a defeasible criterion or rule can (i) apply categorically (or in all-or-nothing fashion) but (ii) not dictate absolutely the outcome of a choice or decision. A countervailing or defeating criterion can cut the other way. While this may seem obvious enough, it is worth re-emphasizing how very different this is from both Dworkin's and Schauer's notion of an all-or-nothing rule. For Dworkin, the all-or-nothing nature of a rule meant that if the facts it stipulated were actually given, then the rule applied,

\footnotetext{
24 For this characterization of defeasibility in some greater detail, see Chapman, "Incommensurability", supra note 22, at 1499-1501, 1507-1514.
} 
and the answer provided by the rule had to be accepted. ${ }^{25}$ When one conjoins this idea with his notion of exceptions, where all exceptions are collapsed into a full articulation of the rule, then one can see, perhaps, why the model of rules is so hegemonic and unattractive for him. For Dworkin, the categorical has become the absolute as well. But under defeasibility the rule can be complete in its categorical application to some partition of alternatives, and yet be subject to defeasance by a qualification beyond the scope of the rule. This twopart structure allows us to make sense of the categorical regularity of rules without falling prey to them absolutely.

For Schauer, rules are all-or-nothing too, but only when they apply. Their dimension of weight allows them to resist calculations of background justification, but only up to some point, not absolutely. This makes Schauer's rules look a little more attractive, but their relationship to background justifications, where they give way according to their weight, lacks any real categorical structure. The value of the rule's entrenchment somehow weighs against the background justification, but is not in any way independent of it. In some respects this lack of independence between the rule and its background justification is parallel to the same lack of independence that exists for Schauer beween a rule and its qualifications. A complete statement of the rule, according to Schauer, simply specifies all of its qualifications. Borrowing from a dichotomy provided by George Fletcher, we might say that the assessment of a rule relative to both its background justification and its qualifications is "flat", not "structured". ${ }^{26}$ That is, all the considerations relevant to these assessments are in play "in a single stage" of analysis. In a structured analysis, on the other hand, the different considerations come in for assessment at different stages, something that keeps these considerations apart from, and independent of, one another. This structure is what is provided by the sequenced priority of defeasible legal rules. Thus, where Dworkin's account of rules has structure and priority without defeasance, Schauer's account seems to allow for defeasance without providing much in the way of categorical structure.

\footnotetext{
25 See supra, text at note 6.

26 George P. Fletcher, "The Right and the Reasonable" Harvard Law Review 98 (1985), p. 949.
} 
While the analysis so far may suggest that Hart's notion of defeasibility can make sense of the categorical nature of rules while allowing for less than their absolute priority, something more can be said to resist the idea, shared by both Dworkin and Schauer, that exceptions should simply be viewed as part of a complete statement of the rule. Again, Hart's contract example is suggestive. Recall that Hart alluded to the broad range of defences that might be relevant (under the various "unless" clauses) to the claim, say, that there was an applicable contract. Hart mentioned in particular duress, lunacy, and fraudulent misrepresentation. Now, some of these do seem to deny the applicability of the contract altogether. One might have a view, for example, that there cannot be a contract with a lunatic. Likewise, the presence of fraud may go to a denial of there being any real meeting of the minds on a common issue, even one objectively considered, something which again would deny the existence of a contract. But duress, depending on how it is interpreted, could operate as a genuine defence, that is, as something which admits the presence of a prima facie contractual obligation, but argues in reply (or in the mode of "confession and avoidance" rather than "denial") that the circumstances were such that the defendant should not be contractually obligated. Indeed, it is tempting to think that some defences must be like this. After all, they are defences, and the very notion of a defence seems, sometimes at least, to presuppose something, namely, that the plaintiff has already established the prima facie case against which the defence must be asserted. One might say that it is the prima facie case which puts such defences properly at issue.

Certainly, this seems true of the defence of excuse in the criminal law. An excuse is an essentially (conceptually) sequenced idea, presupposing wrong. Without wrong already in place and complete, there is nothing to be excused from and, therefore, no need to attend to excuses at all. Thus, if there are rules or normative criteria that form the basis of establishing wrong, then, as a conceptually sequenced matter, these rules or criteria must be complete in their application to the facts before the qualifying criteria, informing the notion of excuse, can properly arise. In this way, therefore, it is clear that some excuses or defences must operate under defeasibility as qualifiers of an independently established (prior, categorical) prima 
facie case. There is no sense in which they can be merely collapsed into the rule rather than stand apart from it.

\section{BACKWARD INDUCTION AND NASH EQUILIBRIUM THINKING}

It is now time to return to the theory of games and to begin considering whether the notion of a defeasible rule or, more generally, the idea of a defeasible regularity condition, can have any application there. Of course, in the theory of games the relevant regularity condition, as already suggested, is the rationality of individual behaviour in the game, and the promise of defeasibility is that it might provide a sensible way to accommodate an irrational move by one of the players in the game.

In this section I will consider a special sort of repeat game which I call the Termination Game. In the Termination Game I will argue that the game theorist's use of the backward induction argument calls for each player to contemplate ignoring his observations of systematically irrational play by the other player even though that irrational behaviour can be the only explanation for being at the end of the game from which the backward induction argument begins. I then argue that the same sort of blind adherence to rationality is used when CKR or CBR is offered as a rationalization to play Nash equilibrium strategies in the purely introspective deliberations that are iterated across the many strategies of a complex one-shot game. Here, because there is no possibility of actual repeat play, the idea is not so much that the players first observe, and then ignore, systematically irrational behaviour, as it is that they contemplate and then ignore the many recursive possibilities of apparent irrationality within a strategically complex game. However, in neither case is the rational player permitted to learn very much, in a forwardly inductive way, from the possibility of irrational play. In the next section of this paper I shall argue that a player armed with a more defeasible conception of rational play, that is, one that allows for a revisable conception of what rationality might require in light of what one learns from the strategy choices of others (observed or not), may well do better, not only in these more strategically complex games, but also in the simple one-shot prisoner's dilemma game. 
The Termination Game is a version of the two person finite repeated prisoner's dilemma game. By this I mean that the prisoner's dilemma game is played a finite number of times between the same two players. Suppose this number is $n$. What gives the game its name is the following supplementary rule: In addition to the possibility of the game ending after $n$ iterations, the game can also terminate earlier if either (or both) of the players choose to play their non-cooperative strategy.

How will the players play this game? The backward induction argument suggests that each of the players will choose the noncooperative strategy at the first play of the game and, therefore, that the game will end there. The argument goes as follows: ${ }^{27}$ Consider the last, or $n$ th, iteration of the repeat game. At this point, with all other iterations already complete, the last iteration is reduced to a one-shot prisoner's dilemma game where defection or noncooperation is the dominant strategy for each of the two players. In this sense, the final iteration is solvable for the two players, and predictably so, since each knows not only what is rational for her there, but also what is rational for the other player who is an equally rational chooser. Thus, their attention turns from the final $n$th iteration, which is solved, to iteration $n-1$, or the second last iteration. But this solves the same way for them as the last iteration. With each player predictably defecting for all the usual reasons of dominance on the last iteration of the repeat game, there is every reason to treat the second last iteration of the game like the last. After all, with the future of the game already determined, what good could possibly come from not choosing the dominant strategy at this penultimate point? Thus, the $n-1$ iteration is solved by the players in the same way as the one-shot game, namely, as one where individual rationality requires each player to choose non-cooperatively. Identical reasoning holds for all iterations back to the first play of the game. Cooperation, according to the backward induction argument, is never individually rational. Thus, the players both play non-cooperatively on the first play of the game and, according to the termination rule, the game ends. The repeat game is effectively reduced to a one-shot prisoner's dilemma.

27 See R. D. Luce and H. Raiffa, Games and Decisions (New York: Wiley and Sons, 1957), pp. 97-102. 
This result must surely give the players reason to pause, particularly if $n$ is large. For, as $n$ becomes large, the possible cooperative gains which are foregone from adopting a non-cooperative strategy in the first play of the game become larger as well, and it becomes correspondingly more difficult to label the non-cooperative strategy as either individually or collectively rational when it is played.

The Termination Game is illustrated in Figure 2 for three possible repetitions $(n=3)$ of the prisoner's dilemma game shown in Figure 1. The rows and columns indicate strategy choices for player Row and player Column respectively. In particular, the row and column labels $n-\mathrm{d}$, for $\mathrm{d}=0,1,2$ or 3, refer to the number of times Row and Column plan to play the Figure 1 game cooperatively $(\mathrm{C})$ before defecting (D). Thus, if each of the two players plan to cooperate for two iterations of the game and defect only on the last (i.e., where $\mathrm{d}=1$ ), then their choices of these strategies would determine an outcome where Row $n-1$ and Column $n-1$ intersect. The payoffs for the different possible strategy combinations for the Termination Game are shown for each outcome in the matrix of Figure 2. Again, in accordance with convention, Row's payoffs are indicated first. (I assume no discounting, so that the payoffs for each player in the repeat game are simply the sum of the payoffs in each iteration of the game that actually gets played.) Thus, where both players choose to cooperate twice and then defect, the Row $n-1$ and Column $n-1$ intersection reveals that each player will get a payoff of 5 from such a strategy combination. Each will get 4 (or $2 \times 2$ ) from cooperating twice plus an additional unit for playing and defecting on the third iteration of the game. On the other hand, if Row plans to defect immediately after the first iteration $(\mathrm{d}=2)$, then Column, even if she plans to play cooperatively throughout all three iterations $(\mathrm{d}=$ 0 ), will only get a payoff of 1 while Row gets a payoff of 6 . This is because, whatever Column's plans for the game, it will terminate with Row's defection at the second iteration. This explains why there is a certain amount of replication of the payoffs within rows and columns of the overall matrix (especially for strategy $n-3$ for one of the players). One player can change his or her strategic plan for the game, but unless the other party also changes, the payoffs will very often remain the same. 


\section{COLUMN}

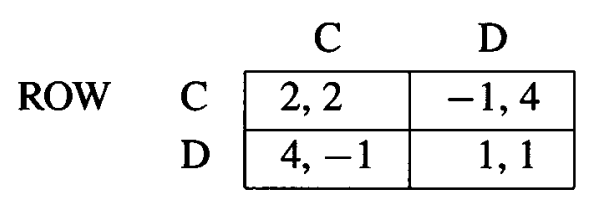

Figure 1. The one-shot prisoner's dilemma.

\section{COLUMN}

\begin{tabular}{|c|c|c|c|c|c|}
\hline \multirow{5}{*}{ ROW } & \multirow{3}{*}{$\begin{array}{l}n-0 \\
n-1\end{array}$} & $\mathrm{n}-0$ & $\mathrm{n}-1$ & $n-2$ & $n-3$ \\
\hline & & 6,6 & 3,8 & 1,6 & $-1,4$ \\
\hline & & 8,3 & 5,5 & 1,6 & $-1,4$ \\
\hline & $n-2$ & 6,1 & 6,1 & 3,3 & $-1,4$ \\
\hline & $n-3$ & $4,-1$ & $4,-1$ & $4,-1$ & 1,1 \\
\hline
\end{tabular}

Figure 2. The termination game.

One can "see" the three iterations of the backwards induction argument in the Termination Game as the three overlapping four cell boxes indicated down the diagonal of the overall matrix. The first step of the backward induction takes the players to the payoff pair $(5,5)$, the second step of the induction to the pair $(3,3)$, and the last step to $(1,1)$. Each of these steps uses what seems to be logically impeccable dominance reasoning. Yet, as already suggested, one cannot help but feel that, as the players are marched logically down the diagonal, they will cast a wistful glance back to the payoff pair $(6,6)$ in the top left hand corner of the matrix which they are so rationally leaving behind them. Is there any rational way back?

Certainly there is some reason to doubt that rationality can so unambiguously take them to the outcome $(1,1)$. For what are we to make of rational players, armed with common knowledge of their rationality, actually contemplating, as the backward induction argument suggests they should, finding themselves at the $n$th iteration of the repeated game? We know what it is that the backward induction argument tells us they will think of, and predict of, each other at that point. Indeed, under the CKR assumptions we are permitted to 
say, apparently, what it is that they will know of each another at that point. In particular, they will know, it seems, that each one of them is rational and will rationally defect in this last round of the game. This is how the backward induction begins and, moreover, how it goes on.

But how is CKR consistent with even contemplating being at the $n$th iteration of the Termination Game? To have reached that point in the game, both of the players will have had to play irrational cooperative strategies in every one of the earlier iterations. Surely, there is some room for doubt about the CKR assumptions here. Yet none of this, according to the backward induction argument, is supposed to shake the confidence of the players in what they know in common of each other's rationality at the final iteration of the game, for it is this very common knowledge of rationality which will allow them, despite every thing that has happened so far in the game, to go on to predict mutual defection in the one iteration of the game that remains, the iteration that is the first logical step of the backward induction. Robert Grafstein puts the point nicely and succinctly: "Backward induction, ironically enough, depends on the unwillingness of the players to make appropriate [forward] inductions". 28

The players in this repeat game seem to have two choices. First, if they are prepared to entertain as a conclusion of their argument a fact which they know in common, namely, that it is rational to play noncooperatively in every iteration of the repeat game, then that fact should be something which can be introduced without contradiction into their argument from the beginning. After all, their argument, as a rational result which can be proved about the game, is also common knowledge in the game. But such a fact, once introduced, would prevent the backward induction argument from getting going; there would no sensible possibility of being at the $n-1$ iteration of the game if it meant that each had cooperated up to that point. Thus, this choice amounts to keeping CKR and giving up on the backward induction argument. ${ }^{29}$

\footnotetext{
28 Robert Grafstein, Institutional Realism (New Haven: Yale University Press, 1992), p. 141.

29 For a similar argument, see Philip Pettit and Robert Sugden, "The Backward Induction Paradox," Journal of Philosophy 86 (1989), p. 169; and Cristina
} 
On the other hand, if the backward induction argument is to be allowed to start, that is, if it is to accommodate the possibility of cooperation so far, then its conclusion, as one of the rational results provable within the theory of the game on what is to play the game rationally, cannot be common knowledge in the game, that is, cannot be a fact that every player knows. Either it is not a fact about the game at all, or it is a fact about the game, but at least one player has beliefs which are at odds with it. ${ }^{30}$ Thus, the second choice amounts to keeping backward induction as used here, but giving up on CKR.

Bicchieri, "Self-Refuting Theories of Strategic Interaction," Erkenntnis 30 (1989) p. 69. The idea that the rational conclusion of the backward induction argument should be capable of being introduced, without contradiction, into the argument from the beginning was argued for originally by Quine with respect to the "surprise hanging" paradox; see W.V. Quine, The Ways of Paradox (Cambridge: Harvard University Press, 1966), pp. 19-21.

30 Either of these last two possibilities would allow ex ante for cooperative play somewhere in the repeat game by either player. It is, of course, well-known that cooperation can result in the finite repeated prisoner's dilemma when the players' rationality is not common knowledge among them; see David Kreps, Paul Milgrom, John Roberts and Robert Wilson "Rational Cooperation in the FinitelyRepeated Prisoner's Dilemma," Journal of Economic Theory 27 (1982), p. 245. What seems less well-known is the fact that the particular form of rationality which is manifested in the backward induction argument cannot (i.e., without contradiction) be common knowledge amongst the players. But this impossibility of common knowledge of rationality in any finite prisoner's dilemma game where either the players play cooperatively in fact, or where they are hypothesized to play cooperatively for the purposes of, say, a backward induction argument, opens up two quite different ideas, only one of which is exploited by the particular "is not" assumptions of Kreps et al. Their argument suggests that the notion of what is rational play in the game is secure as a notion, but at least one of the players simply does not believe the other to be rational in this way (or does not believe that the other believes him to be rational in this way, etc.). Thus, they want to focus on relaxing the "common knowledge" part of "common knowledge of rationality". However, a different possibility is that the very notion of what it is to play the game rationally is less secure than the conventions of rational choice might suggest. It is this latter idea, which takes a second look at the "rationality" part of "common knowledge of rationality", that is being suggested for analysis in this paper. Unlike the former sort of departure from common knowledge of rationality, the latter can countenance the thought that the players beliefs about each other's rationality in the game might eventually align themselves with what actually is rational for each of them in the game as a matter of fact. 
The first of these two choices appears at first sight to be the more tempting. Ken Binmore has referred to CKR as the implicit axiom of all game theory, ${ }^{31}$ whereas the backward induction argument would appear to have only a much more limited application, say, in some repeat games. Moreover, without CKR, that most basic of all game theoretic ideas, the idea of a Nash equilibrium, seems less secure. ${ }^{32}$

To see this last point, consider first the following definition of a Nash equilibrium: "A Nash equilibrium is an array of strategies, one for each player, such that no player has an incentive (in terms of his own payoff) to deviate from his part of the strategy array." 33 This means that, for each player, given the strategy choice(s) of the other player(s), the Nash equilibrium strategy choice is the best possible response by the player. Now, one can easily imagine how this definition captures a plausible notion of "equilibrium". Certainly there is a sense in which each player, for example, can breathe a sigh of equilibrium relief when, having played her Nash strategy, she observes that the other players have played theirs too. By definition, this is the best that she could have done in the circumstances and, once there, she certainly experiences no sense of regret, feeling that she wants now to change her mind.

But in most one-shot games requiring simultaneous play, a player has no real opportunity to change her mind in any case, and so one might legitimately wonder what the real impact of such Nash-like thinking is on the choice of strategies. ${ }^{34}$ This is where the game theorist, armed now with the CKR assumption, comes in. For more

\footnotetext{
31 Ken Binmore, "Modeling Rational Players. Part I," Economics and Philosophy 3 (1987), p. 193.

32 John Nash developed the equilibrium idea which now bears his name more than forty years ago in J. Nash, "Non-Cooperative Games," Annals of Mathematics 54 (1951), p. 286. Shaun Hargreaves Heap and Yanis Varoufakis, Game Theory (London: Routledge 1995), p. 37, refer to it as "the most famous concept that game theory has produced for dissecting games."

33 David Kreps, Game Theory and Economic Modeling (Oxford: Clarendon Press, 1990), p. 28.

34 Compare Hans Jorgen Jacobsen, "On the Foundations of Nash Equilibrium," Economics and Philosophy 12 (1996), p. 68:
}

It does not follow directly from the definition of a Nash equilibrium that equilibrium strategies, or only equilibrium strategies, are sensible candidates for actual play.... Consider a two-player, simultaneous-move game. Why should Player 1 
than this can be said about the Nash strategies. Not only are they equilibrium strategies, such that, once there, one would not want to change one's mind; they are also, the argument goes, the only obvious way to play the game for players with common knowledge of their rationality. This makes the Nash equilibrium idea a much more interesting one. Now Nash thinking can also serve to identify and predict a "solution" for playing the game.

To see this, consider again, for example, the Termination Game matrix shown in Figure 2. Visual inspection of this game shows that it has only one Nash equilibrium, viz., at the payoff pair $(1,1)$ where both players choose never to cooperate. Of course, this is the same equilibrium identified by the backward induction argument, but now, with CKR assumed, there is some further support for this as the only rational way to play the game. For consider any other possible strategy choice combination in the game, for example, that combination which has Row choosing to cooperate twice and Column thrice with the payoff outcome $(8,3)$. How could two fully and equally rational players, with common knowledge of their rationality, possibly choose to play in a way to produce this as an outcome? One can see how Row might, for a brief moment, be tempted to think that he could take advantage of the best possible opportunity in the game for him by cooperating twice and then defecting while Column went on to cooperate again. But Column, almost as soon as this thought even crosses Row's mind, has the same thought about what Row might do. This is what CKR implies. It allows any one player to fully replicate the reasoning of the other, and it is this which does not allow for the (commonly) rational survival of the strategy choice combination leading to the payoff outcome $(8,3)$. For as soon as Row thinks of this possibility, Column thinks of it too, and then Row thinks of Column thinking that; the result is that

play a best reply to the strategy actually played by Player 2, when Player 1 does not know Player 2's choice at the time Player 1 decides his own strategy? ...

In a non-cooperative game each player must make up his mind on what to play and expect others to play on a purely individual basis. On the other hand, a Nash equilibrium is by definition something collective, a collection of strategies with a specific cross player property. The problem of justifying the Nash equilibrium concept is the same as explaining how purely individual considerations may lead each player to play or conjecture his part of such a collective plan.

(Emphasis in the original; footnote omitted). 
Row's initial (one-sided) thought is immediately dismissed from his (their?) commonly rational mind. Likewise, Column might also think for a moment that cooperating only once is the best strategy for her if Row is thinking of cooperating twice, but again Row replicates that reasoning, making impossible what Column hoped to achieve by that strategy choice. This too is something Column sees as soon as Row does. And so on. Indeed, the only strategy combination that can survive these iterations of common rationality is the Nash strategy combination, since here their common rationality forms a closed loop, where each player's (equal and transparent) reasoning receives confirmation from the (equal and transparent) reasoning of the other, and where, therefore, there is no unilateral temptation to wander off to any other combination of strategies. Thus, the Nash combination of strategies not only identifies an equilibrium once it is achieved, it also identifies the only way the players can play the game, at least under the constraints of mutually consistent rational play that are imposed by the CKR assumption.

This makes Nash thinking appear attractive as a way to conceive how two equally rational players might interact. But there are problems. To begin, unlike in the Termination Game where there is a unique Nash equilibrium, in many other games there are multiple Nash equilibria. This is an embarrassment of riches, and much of contemporary game theory is involved in the project of "refining Nash equilibria", that is, of selecting out some subset of all those equilibria which are available in the game as somehow "more sensible" than others. But this project of Nash refinement has generated its own set of difficulties. Consider the following remarks from David Kreps, himself one of the major contributors to the refinement project:

The main point is that we depend in many economic applications of game theory on refinements such as backwards and forward induction (and more complex variations on these themes) to select among Nash equilibria. Such refinements are usually based on the assumption that observing a fact that runs counter to the theory doesn't invalidate the theory in anyone's mind for the 'remainder' of the game. Put another way, these refinements have us and the players employing 'business as usual' arguments following the demonstration that business is very much unusual without giving any reason why. This is not a very satisfactory state of affairs. ${ }^{35}$

35 Kreps, supra note 33, at 113-114. 
Similar concerns about the direction taken in much of recent game theory have been voiced by Ken Binmore, ${ }^{36}$ Philip Reny, ${ }^{37}$ and Robert Sugden. ${ }^{38}$

By now all this should sound a little too familiar. While we began above with the first choice of abandoning the backward induction argument and hanging on to CKR, because the latter seemed so essential to understanding what was attractive about Nash thinking, we now find that the project of refining Nash thinking, so that it can be a little more discriminating, brings us right back to backward induction. But this sort of argument, as Kreps reminds us, has the oddity built into it that rational players learn very little, in a conventionally forward inductive way, from persistent counterexamples to their theory of rational play.

Is it time to re-consider the first of the above two choices, that is, to allow in the possibility of backward induction, but to relax CKR, at least in so far as the latter requires each player to know in common with the others that all players in the game are rational? CKR could be relaxed in either of two basic ways. First, one could relax the players knowledge of rationality. This in turn could be accomplished by either relaxing some fact about one of the players actually being rational or by hanging onto those facts of rationality but giving up the players common knowledge of them. The second basic way to relax CKR is to admit all common knowledge (and, therefore, truth) of rationality, but to relax the very notion of rationality itself, at least as this is conventionally understood. Most rational choice theorists,

\footnotetext{
36 Binmore, supra note 31.

37 Reny, supra note 2. Compare Reny's characterization (at note 3 in his article) of one of the best known of the Nash refinements, the so-called "subgame perfect Nash equilibrium", with the remarks provided by Kreps in the text:
}

That is, not only must it be that (i) every player has decided what to do in every possible eventuality so that from his perspective at the beginning of the game his choices are best given what the others have planned to do, it must also be that (ii) whenever any possible eventuality becomes a reality, no player will wish to change his previously decided upon choice. (emphasis added to the original)

\footnotetext{
38 Robert Sugden, "Inductive Reasoning in Repeated Games", in Reinhard Selten (ed.), Rational Interaction: Essays in Honour of John C. Harsanyi (New York: Springer-Verlag, 1992).
} 
not surprisingly, adopt the first of these two basic choices. ${ }^{39}$ As I shall try to suggest in the next section of this paper, there may be some advantage to at least considering the second.

However, it will be objected even now that we have forgotten one of the reasons why we chose to relax backward induction rather than CKR in the first place. Was not backward induction only of use in a repeat game? And was not CKR, in its support for Nash thinking, much more generally useful, that is, in repeat and oneshot games alike? It might be thought that much of what has been said so far about the incoherence of resiliently holding onto CKR assumptions in the repeat game cannot be extended to the one-shot game since there is no possibility of observable behaviour which can, or should, rationally induce a player to give up her beliefs (and, therefore, her knowledge) in the rationality of another player (or, at least, her beliefs in that other player's beliefs in her own rationality, and so on). Put simply, in a one-shot game there is no possibility of an intervening observable fact which can induce a rational player, as the game goes on, to question what she thought she knew and, therefore, to reconsider what she now rationally should do in the face of this new knowledge. Thus, the rationality of choosing, say, the defection strategy, might still be thought to be more secure in the one-shot prisoner's dilemma game than in any of the repeat form versions of that game.

However, there is reason for doubting that there really is this difference between the two sorts of games. For a start, it is important to be clear that the backward induction argument, at least as it operates in the Termination Game, is entirely introspective. What each player reasons about in this repeat game is only the possibility of playing the $n$th iteration of the game; for, according to the backward induction argument, that iteration will never actually be reached. Indeed, since only the first iteration of the game actually gets played, what is observed in this potentially repeat game is exactly what one observes in the one-shot game. The only difference between the two is that, in the repeat game, the players' backwardly inductive introspections about the possibilities of repeating the game drive them to defect in that first iteration so that, under the termination rule, these possibilities are never realized and the repeat game is

39 See, e.g., Kreps et al., supra note 30. 
reduced to a one-shot game. Thus, if there is something problematic about the use of the backward induction argument in the Termination Game, and we have already suggested that there is, then it cannot be that there is an odd "business as usual" attitude in rational players, resiliently confident of each other's rationality, actually confronting externally observable behaviour which runs counter to what such players would rationally predict of each other. That is, it is not merely as if there is some tension or inconsistency here between logically tight backward induction (which calls for universal defection) and empirically based forward induction (which builds on some amount of observed cooperation). Rather, under the backward induction argument as used in the Termination Game, where only a first iteration defection is ever observed, and where the backward induction argument is only used introspectively, it is more that there is some internal inconsistency within the backward induction argument itself, namely, that the argument both assumes and denies a rational player capable of cooperation.

Moreover, this same inconsistency is present in Nash equilibrium thinking under CKR. Again, what such thinking requires is that each player consider what a rational player would do at a point in the game which cannot even be entertained as a logical possibility if players were rational in the way assumed. This internal inconsistency in the argument is something each player who uses CKR confronts individually even as she reasons intersubjectively in the way that CKR suggests; it requires no actual social interaction (no objectively significant act) between the players as each observes (over the course of a repeat game) the actions of the other.

However, now the claim will be that the real problem is that the internal inconsistency can only arise in a strategically complex game, that is, where there is some rich space of alternative strategies, now not actually played of course (as in the actual repeat play games), but still logically possible. For it is only then that there is the real possibility of inconsistency in both assuming the rationality of a player at some strategy choice and denying the possibility that a rational player could ever reach (i.e., consistently contemplate) that strategy choice. In a more simple game, where, for example, there is only one choice to be made between two strategies, as in the one- 
shot prisoner's dilemma, there would be no room for this kind of internal inconsistency across strategy choices.

Moreover, it will also be said that any possible internal inconsistency in the backward induction argument as used in repeat games, or in CKR as used in Nash equilibrium thinking for strategically complex one-shot games, is simply irrelevant to the dominance thinking that is used in the one-shot prisoner's dilemma. After all, in the one-shot prisoner's dilemma game each player has reason to choose non-cooperation regardless of what the other chooses and regardless, therefore, of how rational that other player is or is believed to be. Thus, since CKR plays no role in how the prisoner's dilemma is solved, a relaxation of CKR, even if required for reasons of internal consistency for more strategically complex games, cannot have any necessary implications for how we understand and solve the more simple game. Or so the argument might go.

The response to these objections depends on how we relax CKR to avoid the internal inconsistency. In the next section of the paper I will suggest that a sensible case can be made for relaxing CKR, not by relaxing the commonality of knowledge or belief, but, more radically perhaps, by relaxing what there is to be common knowledge of, namely, the very notion of rationality itself. This apparently more radical relaxation of CKR, while not required by the arguments so far, focused as they are on repeat or strategically complex games, would, nevertheless, have implications for rational play in a simple one-shot prisoner's dilemma game.

\section{REVISABLE RATIONALITY IN A ONE-SHOT GAME}

Imagine what it could mean to relax CKR for each player in the one-shot prisoner's dilemma game. Two general possibilities have already been mentioned, and the first is merely this: that each player, secure in her own knowledge of what rationality properly requires, cannot know that the other player in the game is also rational in this way or, at least, cannot know that the other player believes her to be rational in this way. But this would change very little how each player would think about how to play the one-shot game. For, recall, this game is solved by dominance reasoning, something 
which allows a player to choose the dominant strategy regardless of what strategy the other player might choose to play, and however rational or irrational the other player is (or however rational or irrational that other player thinks the first to be). Thus, this way of relaxing CKR in the one-shot prisoner's dilemma really has no implications at all for how a rational player should play the game; CKR is simply irrelevant to the matter.

However, now consider the second possible way of relaxing CKR in such a game. Consider that each player entertains this seemingly more radical thought, namely, not that she simply does not know that the other player in the game is rational (or believes her to be rational), but that she does not know herself what it is to be rational in the game. This possibility, while apparently more radical than the first, should not be overstated. It is not required that she think she does not know what rationality requires of her at all. All that is required is that she give up her unwavering belief, her absolute confidence, in what rationality implies. ${ }^{40}$ She must entertain (reasonably, open-mindedly, rationally ${ }^{41}$ ) at least the possibility that she might be wrong, not merely about the rationality of another in the game, but about rationality itself.

This "more radical" way of relaxing CKR in the one-shot prisoner's dilemma game might well change how such a more modestly confident player would play the game. For now her doubts about what rationality requires of her, unlike mere doubts about the rationality of the other player, may unsettle her views about the dominance thinking that recommends unconditional defection as the only rational choice of strategies. Indeed, the two ways of relaxing CKR might usefully be linked in the following way. The first way of relaxing CKR might open up in the mind of each player the

\footnotetext{
40 Even this way of putting the point equivocates between a player (i) being uncertain about what rationality is and (ii) being certain of that in general, but being uncertain of what that implies for her own rational play in a (any?) particular game.

41 Richard Rorty has characterized the rational person as someone willing to listen and be open to the views of others in his "Science and Solidarity" in John S. Nelson et al. (eds.), The Rhetoric of the Human Sciences (Madison: University of Wisconsin Press, 1987), p. 38. I prefer to think of such a person as "reasonable", reserving the term "rational" for the more conventional (and unbending) chooser of rational choice theory.
} 
possibility that the other player will not play the dominant defection strategy that conventional rationality recommends. And the second more radical way of relaxing CKR might suggest this as the explanation: that the rational way to play the game is not defection, as dominance recommends, but cooperation, as some other (still unarticulated) account of rationality recommends. Indeed, it could be, contrary to the dominance thinking in the one-shot prisoner's dilemma, which recommends the same strategy regardless of what the other player does, that this more radical way of relaxing CKR will allow for the possibility of recommending a different strategy in the face of the other player's cooperation than it does in the face of the other player's defection. ${ }^{42}$

This way of thinking, which allows for a revision of what rationality requires depending on what one observes or contemplates of the other player, should remind us of the legal theorist's conception of defeasible rules. On the one hand, there is the priority of a given conception of rationality, or regularity, which in so far as it goes unchallenged by any countervailing particularity, or recalcitrant experience, allows us, confidently and categorically, to proceed. It is not as if we had no conception of rationality at all to begin with. On the other hand, faced with some such recalcitrant experience, there is also the possibility of revision or defeasance of our prior conception of what rationality or regularity requires.

Suppose that the rules of rational choice were more like this account of defeasible legal rules. Suppose, in particular, that one of the players in the prisoner's dilemma, while guided by the traditional rules of rational choice, took them only as prima facie evidence of what it was rational for her to do in the situation. How would such a player react to the possibility of cooperative play by the other player, a player exactly like herself and, more particularly, a player seemingly just as rational as herself? Arguably, such a player might begin to wonder whether rationality actually required defection in this situation.

\footnotetext{
42 It is worth noting that this new account of rationality is just as much at odds with a Kantian approach, which recommends unconditional cooperation (i.e., recommends it as a "categorical imperative") as it is with dominance thinking, which, just as unconditionally, recommends defection.
} 
Certainly, with any given rule of rational choice only operating, for each player, as a presumption of what rationality actually requires, the fact that the other identically situated player, who is apparently just as rational, has played cooperatively, or in a way other than what the rules of rational choice resumed by the first player to suggest, is grounds for the first player to reconsider what the rules of rational choice, properly construed, actually recommend. Perhaps such cooperative play by the other player is some evidence that the rules of rational choice are actually different from what the first player thought them to be. At a minimum, we have made some room, within rational choice, for a little helpful forward induction. ${ }^{43}$

We may even have made some room for announcing a different rule of rational choice. For example, a rule which has each player defect when the other player defected (since in such a case there would be no evidence countervailing the thought that rational choice required defection), but which has each player cooperate when the other player cooperated (since in this case there would be some reason now for questioning whether defection is in fact the rational choice), might be reasonable. ${ }^{44}$

43 See Binmore, supra note 31, at 203: "One might say that she is subject to trembles in what she supposes to be the correct way to play." It is worth noting that these are "trembles" which go to the definition of what is rational. Thus, they are very different from the trembles introduced by Reinhard Selten, "Reexamination of the Perfectness Concept for Equilibrium Points in Extensive Games," International Journal of Game Theory 4 (1975), p. 25. According to Selten, trembles are a kind of mistake which go merely to the execution of choices which rationality properly identifies, a bit like pushing the wrong button. But this means that the probabilities of mistakes in different plays of the game will be independent of one another, something which makes reaching the final iterations of a repeat game under the termination rule increasingly unlikely. On this, see Jon Elster, The Cement of Society (Cambridge: Cambridge University Press, 1989) p. 6. Thus, a forceful explanation of actually reaching these iterations requires a tremble over something much more systematic, like the notion of rationality itself. This is what is being emphasized by Binmore, and by the argument in the text.

44 This will sound like the structure of the assurance game; see Amartya Sen, "Isolation, Assurance, and the Social Rate of Discount," Quarterly Journal of Economics 80 (1967), p. 112. However, it is important to appreciate that the structure of the game being discussed in the text is still that of a prisoner's dilemma. What gets changed, according to the argument, is what counts as rational behavior within that game. For the same reason, the solution being 
Moreover, we might even be able to explain this equivocation between cooperation and defection in the following way. ${ }^{45}$ Suppose that a player in the prisoner's dilemma believed that, as an individual, one could act rationally either by acting individually or by acting collectively. Individually rational action is what is illustrated by dominance reasoning: the individual player is better off regardless of what the other player chooses to do. But an individual might act rationally in a collective way if she thought her conduct was

$\overline{\text { proposed }}$ in the text differs from that offered in the theory of psychological games; see, e.g., Peter Huang and David Malueg, "Psychological Remorse in the Prisoner's Dilemma and Folk Theorems for Psychological Games" (manuscript, Department of Economics, Stanford University, 1994). In the theory of psychological games, expectation-dependent remorse (or regret) for having defected (cooperated) when the other player cooperated (defected) has the effect of changing the outcomes in the game so that they approach that of an assurance game.

This is also a convenient point to emphasize that what is being proposed here is different from what evidential decision theorists propose for the prisoner's dilemma. Evidential decision theorists argue that the probability assigned to an outcome or a strategy choice by another player need not be independent of the first player's chosen strategy even though there is causal independence between the two. (This causal independence, of course, is exactly what causal decision theorists emphasize as good reason for assuming probabilistic independence and, therefore, for choosing the dominant strategy in the prisoner's dilemma.) Evidential decision theorists would allow the first player to assign, say, a higher probability to the other player choosing to cooperate in the prisoner's dilemma if the first player cooperates, something which can then make it rational to cooperate on conventional expected utility grounds. For good discussion of evidential and causal decision theory, and for an all-embracing decision-theoretic analysis which finds a place for both, see Robert Nozick, The Nature of Rationality (Princeton: Princeton University Press, 1993), pp. 41-63.

However, in the argument being proposed in the text, just as the outcomes are not changed (so that the prisoner's dilemma becomes, say, an assurance game or a game where defection is associated with remorse), so the probabilities assigned to the outcomes also remain unchanged. Rather, what is changed under the proposed analysis is the status of the rules of rational choice which are brought to bear on the original prisoner's dilemma game. In the face of apparently irrational cooperation, a player reconsiders what constitutes rational choice.

45 The following discussion borrows from Susan Hurley, "Newcomb's Problem, Prisoners' Dilemma, and Collective Action” Synthese 86 (1991), p. 173. Hurley explicitly distinguishes her attempt to ground cooperative action in the prisoner's dilemma from attempts made within evidential decision theory. On the latter, see supra note 44. 
more rational when it was a meaningful part of some larger whole, an enterprise of like-minded cooperators, for example. ${ }^{46}$ Again, her doubts about where rationality lies might be a function of the cooperative behaviour she observes in others. If others defect, then she not only loses the cooperative whole of which she wants to be a part, but she may well begin to doubt that cooperation based on

46 Shafir and Tversky have uncovered an interesting behavioral anomaly which may be relevant here; see Eldar Shafir and Amos Tversky, "Thinking Through Uncertainty: Nonconsequential Reasoning and Choice," Cognitive Psychology 24 (1992), p. 449. In a series of one-shot prisoner's dilemmas, their experimental subjects consistently revealed that while they would tend to defect if they knew the other player had defected and, equally, would tend to defect if they knew the other player had cooperated, they would defect less frequently if they were uncertain about which of these two events had occurred. This "disjunction effect", which they find in a variety of contexts, appears to violate what is known as "the sure thing principle", a cornerstone of expected utility theory. The explanation offered by Shafir and Tversky (id., at 457) for the disjunction effect in the prisoner's dilemma is interesting:

Our subjects seem to exhibit a change of perspective that may be described as a shift from individual to collective rationality. Once the other's strategy is known, a player is "on her own." Only one column of the [prisoner's dilemma] table is relevant (that which corresponds to the strategy chosen by the other), and the outcome of the game depends upon her and her alone. The individually rational strategy, of course, is to [defect]. In the disjunctive condition, on the other hand, all four cells of the table are in play. The outcome of the game depends on the collective decision of both players, and the collectively optimal decision is for both to cooperate. Thus, the pattern of behavior observed in the [prisoner's dilemma] may be explained, in part at least, by the greater tendency to adopt the collective perspective in the disjunctive version of the game.

One can imagine this effect varying a great deal with the context. For example, while many of us know (for all intents and purposes) that our vote cannot make a difference to the outcome of a large political election, and would not bother to vote once the outcome (whatever it is) is determined, we are inclined, nevertheless, to vote when the outcome of the election is still pending. This much is consistent with Shafir and Tversky's results. But in other contexts, for example, where there is an ongoing collective effort that one can continue to be a part of, one can easily imagine someone cooperating even beyond the point where the outcome is still pending, i.e., to the point where cooperation by others has become certain. This may not be consistent with the disjunctive effect observed by Shafir and Tversky, but it is still, arguably, consistent with the collective rationality perspective to which they refer. 
collective rationality could possibly be rational for her; this may induce her to defect. On the other hand, if others cooperate, then the collective view of individual rationality, which induces her to cooperate, is reinforced. The result, again, is that the player may not have a dominant strategy in the game.

It has to be conceded that these arguments for reconsidering the rationality of choosing, unquestioningly, the dominant strategy in a one-shot prisoner's dilemma game are not without serious problems. For a start, a choice of strategy which is completely conditioned for each player by the choice of the other player is dangerously self-referential. It leaves each player suspended in strategic limbo, unable to decide what she should do until the other player, himself waiting for her decision, chooses so as to determine the condition upon which her own decision depends. ${ }^{47}$ However, this objection, while it recognizes the defeasance aspect of defeasibility, ignores too much its other aspect, namely, that which provides for a kind of default or sequenced priority for one of the two notions of rational choice. Absent a decisive consideration to the contrary, one of the two notions of rational choice is to prevail as a rule.

But now the question will arise as to what could possibly count as a "decisive consideration to the contrary". If this can refer only to a countervailing choice by the other player, then in a one-shot game (where there is only one moment of choice) there would be no room for defeasance at all. The default rule of rationality, for example, the one recommending defection, would simply prevail.

However, that seems to be too restrictive an interpretation of the possibilities. A player could work with a defeasible conception of rationality in the one-shot prisoner's dilemma, allowing her choice to condition on what the other player signals as rational by way of his own behaviour, but look beyond behaviour, say,

\footnotetext{
47 See Govert Den Hartogh, "The Rationality of Conditional Cooperation," Erkenntnis 38 (1993), p. 405 for further development of this argument. See also Karl Warneryd, "Rationality, Transparency, and Evolutionary Selection", in Manfred E. Streit (ed.), Cognition, Rationality and Institutions (Jena: Max Planck Institute, Symposium Proceedings, forthcoming 1999), for this criticism of conditional cooperation as well as a prescription for avoiding the problem based on the partial transparency of signaling one's intention to adopt the conditional strategy. For sympathetic comment on the latter approach to the problem, see Bruce Chapman, "Rationally Transparent Social Interactions" in id.
} 
to verbal exchanges, to see considerations indicating behaviour which countervails the default rule. Of course, within the conventions of non-cooperative game theory, it is claimed that such verbal exchange (if it does not change the payoffs in the game) is no more than "cheap talk" and, as such, cannot alter the outcome of the game. ${ }^{48}$ But, contrary to the claim, there is some evidence that such talk does systematically alter behaviour. ${ }^{49}$ Thus, we should not, in the final analysis, shy away from our proposed solution to the self-referential problem of mutually conditioned cooperation for this reason. It seems to have no basis in fact.

More important for what has so far been argued in this paper, however, is the view that there is everything in the difference between arguing for the relaxation of CKR because of the problematic nature of backward induction in some strategically rich games and arguing against the compelling nature of dominance reasoning in the one-shot prisoner's dilemma game. Indeed, this is really the difference between the first way to relax CKR, by relaxing common knowledge without relaxing rationality, and the second "more radical" way of relaxing CKR, which is involved in relaxing the very notion of rationality itself. Surely, it will be said, my argument makes too little of this important difference.

The difference is large, but there is this reply, a reply which, ironically enough, seems to have some (although obviously not all) of the original spirit of the CKR assumption and the support that this assumption provided for the Nash equilibrium as the way for rational players to play the game. The first seemingly less radical way of relaxing CKR contemplates the possibility of each player, still completely confident of her own grasp of what rationality requires, being uncertain that the other player is equally knowledgeable. It is this asymmetry of rational belief which the CKR assumption originally precluded, requiring instead that there be equal (or common) knowledge in all the players. However, the

\footnotetext{
48 Ken Binmore, Playing Fair (Cambridge, Mass.: MIT Press, 1994), pp. 191194.

49 See, e.g., J. M. Orbell, R. M. Dawes, and A. J. C. van de Kragt, "Explaining Discussion-induced Cooperation," Journal of Personality and Social Psychology 56 (1988), p. 811. For analysis as to why this might be so, see Allan Gibbard, "Norms, Discussion, and Ritual: Evolutionary Puzzles," Ethics 100 (1990), p. 787.
} 
second allegedly more radical way of relaxing CKR goes some way towards preserving the original symmetry of CKR. Each player now has equal conviction, and doubt, about what rationality requires of him as an equally rational player. It is this equal possibility of conviction and doubt which raises the possibility within each player of making only a conditional (defeasible) commitment to defection in the one-shot prisoner's dilemma game, a commitment that can at least be partially shaken if the other equally rational player chooses to play cooperatively. Thus, by preserving the commonality of belief across the players while at the same time relaxing what it is a common belief of, the second method of relaxing CKR preserves the form, or structure, of the original CKR and merely gives it some new content. Seen in this way, it is less clear that this really is the "more radical" of the two ways to relax CKR.

Indeed, it might now be argued that, first, given the structure of commonality in CKR, the defeasible conception of rational choice is the only conception of rationality which can provide an internally consistent content appropriate to that structure for strategically complex games. And, second, given that conception of rationality, it would seem to be terribly ad hoc not to extend it to the players in the one-shot prisoner's dilemma game. Of course, it is an added bonus that defeasible rational choice, unlike conventional rational choice, also seems able to make sense of what we actually observe when these games are played experimentally.

\section{CONCLUSION}

In this paper I have tried to argue that the special sort of structure that links legal rules to their exceptions, namely, the structure of defeasibility, provides an account of rule-based decisionmaking which is not exactly equivalent to rule-bound decisionmaking, that is, to invariably following the rules. That is, while defeasibility provides conceptual space for the categorical guidance of rules, it also allows for their non-absolute character, or their revision in the face of countervailing factors.

I have also argued that something like a defeasible conception of rationality is what is required for the theory of games. What is needed there is a conception of rationality that, like rules, is suffi- 
ciently strong to provide some prima facie guidance for conduct at various points of choice, while at the same time not so strong as to preclude (empirically or logically) the possibility of being at those points of choice at all. ${ }^{50}$

That we can find this connection between legal rules and conceptions of rationality should not be as surprising, perhaps, as we might have first thought. After all, both legal rules and the rules of rational behaviour seem to require that some independent attention be given to both (an overlying) regularity and (an underlying) particularity.

Under the descriptive account of legal rules, for example, the particular case sets the standard for the rule. A rule will fail as a description, or fail to provide a proper understanding of the case law, in so far as it is an inaccurate representation of what is actually going on in the cases. On the other hand, under the more prescriptive or normative account of legal rules, where rules are said to provide reasons or justifications for deciding cases one way rather than another, this relationship between a case and the applicable rule is reversed. Now the rule sets the standard for the case.

There is the same equivocation between description and prescription in our understanding of the rules of rational behaviour. At times they are advanced merely as rationalizations, that is, as regularity conditions, helpful to our understanding of an individual's behaviour and capable of providing useful predictions. However, here particularity will ultimately govern regularity. If our predictions fail in any specific situation, we feel obliged to reconsider our account of the rule. At other times, though, the rules of rational behaviour take

\footnotetext{
50 See Elster, supra note 43, at 5, 7 for a comparable demand of rationality theory. Amartya Sen also seems to be looking for an inherently ambiguous notion of rationality so that he can better deal with the problem of counterfactuals, that is, instances of choice which do not seem to correspond with a fully reflective rationality; see Amartya Sen, "Rationality and Uncertainty," Theory and Decision 18 (1985), pp. 109, 112-113. In Binmore, supra note 31, at 198, the idea that "imprecisions are necessarily intrinsic to any properly based theory of rational behavior" is effectively related to the more general philosophical claim that a background theory, whose parameters can be varied, is needed if we are to account for meaningful counterfactuals; on this see David Lewis, Counterfactuals (Oxford: Basil Blackwell, 1976). Defeasibility is not exactly "imprecision" (one hopes), but its dual aspect does capture something of Lewis's idea that counterfactuals must, nevertheless, be meaningful in their countervailing effect rather than merely non-sensical (i.e., beyond the theory altogether).
} 
on a distinctly normative aspect, providing a reason for thinking that the individual should act in a certain way in a particular situation and criticizing him if he does not. Here regularity (even if it is the "thin" regularity of preference transitivity or choice consistency) governs and conditions particularity.

It would appear, therefore, that both legal rules and the rules of rationality are neither wholly descriptive nor wholly prescriptive in nature. In this they are quite different from both from scientific laws, which are taken to provide descriptions of what "is", and from moral laws, which are thought to provide prescriptions for what "ought" to be. Both legal rules and the rules of rationality seem to bridge this is-ought divide. It should not be surprising, therefore, that legal rules and the rules of rationality might have a common structure, and that this structure, a structure that needs to accommodate both regularity and (an independent) particularity, might be provided by the concept of defeasibility.

Faculty of Law

University of Toronto

84 Queen's Park, Toronto

Canada M5S 2C5

bruce.chapman@utoronto.ca 